\title{
The Role of the Strategic Corporate Accelerator: Overcoming Obstacles of Corporate Startup Engagement
}

\author{
Jacob Hornberger \\ Copenhagen Business School \\ jacob.hornberger@gmx.de
}

\author{
Yannik Mack \\ Copenhagen Business School \\ yannik.mack@gmail.com
}

\author{
Abayomi Baiyere \\ Copenhagen Business School \\ aba.digi@cbs.dk
}

\begin{abstract}
Despite the recent emergence of Corporate Accelerators (CA), scholars and managers have questioned their effectiveness. This critique arises from the superficial and inadequate design recommendations that have left many CAs faltering. We explore how strategic CAs in the context of digital transformation can be designed to become effective open innovation units by offering a new conceptualization of the role of the strategic CA. Our multi-case study of four European CAs with a focus on IT startups reveals three underlying obstacles: (1) missing engagement of corporate employees, (2) difficulty of sourcing the right startups, and (3) differences between large firms and startups. Based on these, we propose a framework that captures the role of the strategic $C A$ in correspondence with the identified obstacles. By emphasizing the CA's role, we propose three essential tasks (motivating, matchmaking, and mediating) that are pertinent in the relationships between stakeholders in a CA ecosystem.
\end{abstract}

\section{Introduction}

The combination of digitalization and venture capital has ushered in an era of entrepreneurship [1] in which startup accelerators have gained popularity [2]. The emerging relevance of startups and accelerators plus the increasing pressure for large firms to innovate have resulted in amplified demand and perceived opportunity in their collaboration [3]. Among the predominant vehicles for outside-in open innovation (OI), the corporate accelerator (CA) has evolved as an OI program for established firms to access entrepreneurial innovation $[4,5]$. Despite the burgeoning interest in CAs by researchers and managers alike it is relatively little explored [2, 6], which suggests the need of conceptual and practical toolkits to guide future research and practice.

This is important because an examination of the CAs listed in the CA database Corporate Accelerator
$D B^{1}$ in 2016 shows that, $52 \%$ of the listed CAs can no longer be found and, therefore, likely have been discontinued or entirely realigned. In line with this, Kurpjuweit and Wagner [7] argued that existing programs have been adjusted due to dissatisfaction with and low success rates of current initiatives. This observation highlights the immense changes, volatility, and uncertainty [3] that characterizes the emerging phenomenon of CAs and suggests a need for further research to re-evaluate the assumptions underpinning the current designs and formats of CAs [8]. Moschner and Herstatt [9] provided further evidence to this trend and surmised that CAs are engaging in entrepreneurial washing - because firms often represent and design CAs as a symbolic action with marketing and branding as the underlying motivation and outcome.

Furthermore, prior CA literature has been criticized for the fragmented and contradictory typologies and a lack of a deeper conceptualization of the specific roles, and challenges associated with CAs $[10,11]$. This may be attributed to an extensive stream of CA literature adopting the design elements from the independent accelerator literature to the $\mathrm{CA}$ phenomenon (e.g., $[2,12,13])$. This implies that the CA literature lacks an adequate conceptualization on the key considerations for designing CAs. This relates to calls by scholars on the need to differentiate between strategic and financial-driven CA programs as they follow distinct logics $[4,14]$, and the design elements effective for independent accelerators not being fully applicable to strategic CAs [15]. This indicates a need to distinguish between strategic and financial CAs to avoid comparing apples and oranges.

We address these issues, by analyzing how strategic CA programs can be understood more profoundly with regard to their underlying roles, inherent obstacles, and potential success factors. The sought understanding should reveal implications on the optimal design that are not superficial but anchored in the core of the construct, hence our guiding research

\footnotetext{
${ }^{1}$ https://corporate-accelerators.net/database/
} 
question is: "What are key considerations for the effective design of strategic CAs?"

Our study augments existing research by providing insights into some fundamental and underlying aspects of strategic CAs grounded in an explorative multi-case study of four European CA programs. We found that it is not the individual design manifestations per se that makes a CA an effective tool for OI but the optimal fulfillment of the underlying role of the strategic CA. This role is realized by fulfilling three essential tasks: matchmaking, mediating and motivating which are in correspondence with the underlying obstacles inherent in the collaboration between startups and incumbent firms.

\section{Theoretical Background 2.1 Conceptualizing Corporate Accelerators}

The most renowned definition of accelerators stems from Cohen and Hochberg [16] who referred to accelerators as a fixed-term, cohort-based program supporting new ventures to define, build and scale their initial products or services [16]. This conceptualization has further been applied to the concept of CAs, described as outside-in OI programs for corporates to engage with startups [5] and as "programs of limited duration that support cohorts of startups during the new venture process via mentoring, education, and company-specific resources" [17, p.348]. However, the respective terminology has been controversially discussed in scientific literature so that results have not been uniform, and CAs remain to be dissentingly defined (e.g., [2, 6, 13, 16, 18, 19]). In fact, the current scientific definitions are deemed to be problematic as "conceptualizing accelerators in terms of what they are not (i.e., not incubators) or by where they are contextually situated (differentiating between types of accelerators) fails to explain what acceleration really is" [6, p.19]. Hence, CAs need to be understood as a next generational model of incubation within the corporate context, where strategic objectives, such as OI and organizational learning (OL), and processual factors, such as being time-limited, are considered to shape its distinct character and, thus, the design of this specific startup engagement vehicle in line and in contrast to independent accelerators.

2.1.1 The Strategic CA: There is evidence in literature $[4,7,14]$ that it is pivotal to differentiate between financial CAs targeted towards accelerating the venture emergence itself and strategic CAs primarily targeted towards accelerating the strategic fit of the collaboration between the startups and the corporate [4] or the integration into the parental firm's value chain [7]. Due to this difference in objectives and the underlying logic as well as their influence on various design elements, Kurpjuweit and Wagner [7] have argued that this form of startup engagement cannot even be considered corporate acceleration and should instead be regarded as an entirely new form of startup engagement [7]. Thus, our focus is entirely on strategic CAs, which are insufficiently researched and most promising to foster OI [4].

There is consensus among scholars that both financial and non-financial metrics are deemed to be important outcomes in a strategic CA [4, 6, 13, 23]. The latter in particular seems to be very well suited for assessing the success of OI goals which represents a critical target to be measured [20]. Crișan et al. [6] identified that success measures within CA are often financially focused, biased, and not researched well enough. Further, they find a common tendency to confound outcomes (long-term value for the parental firm through innovation) with outputs (e.g., short-term financial returns, number of startups accelerated), due to output-based metrics which display an increased focus on economic and rather hard than soft outcomes, which may be contradicting for the strategic intent of strategic CAs [6]. These misconceptions help explain, to some degree, the paucity found in existing research to imply the performance of strategic CAs and their outcomes. Hence, there is a lack of research suggesting appropriate concepts for success measures in the context of CAs [20, 22, 24, 25].

2.1.2 The Design of Strategic CAs: As the underlying strategic objectives and types of CAs differ significantly, there has been strong scholarly interest in identifying the design elements of CAs and their manifestations in practice $[14,17,20]$. The names (e.g. design configurations, dimensions and considerations) and reasons for establishing and utilizing these design elements (e.g. classification and recommendations) vary. However, the conceptualizations are similar as they list elements and characteristics of CAs often adopted from the independent accelerator literature, which the sponsors of the CA can actively configure to design these in a certain way to achieve the desired objectives effectively. In this paper, the latter are referred to uniformly as design elements.

While early research has considered accelerators to be homogenous in their design, scholars argue that differences in the funding sponsors and objectives of accelerators lead to heterogenous designs, which in turn influence accelerator performance [12]. Pauwels et al. [13] find that the underlying objectives and design themes of CAs determine the orchestration of the different design elements (cf. [20]). This exemplifies the underlying logic behind clustering CAs into types or design themes. Hence, several and 
partially contradicting CA typologies could be identified in the literature that exemplifies the scholarly heterogeneity among the different typologies of CAs and the concept of CA in general. This might be attributed to the need of scholars to cluster CAs by the criteria relevant to them and their angle of observation, as well as caused by the CA phenomenon being young and still in an era of ferment, leading to the emergence and disappearance of different subtypes of CAs and changing criteria of differentiation among them. The prior literature uses typologies to describe and explain the different manifestations of the design characteristics of CAs $[14,21]$.

A review of the $\mathrm{CA}$ literature makes it evident that the design elements in the literature are partly based on the independent accelerator literature [12] or on a financial rather than strategic logic of the CAs [14]. This is in line with Jackson and Richter [18], who found that the program design of CAs is often inspired by and modeled upon independent accelerators. However, although the phenomenon of independent accelerators is highly successful, it is questionable if this approach, design, and techniques are at all transferable to the corporate context [22] and, if so, to what extent. Therefore, the literature's identified design elements and considerations may be more applicable to categorize CA programs and create typologies rather than to understand or imply an effective CA design.

\subsection{Outcomes of Corporate Accelerators}

2.2.1 Knowledge Creation \& Transfer: When initiating a CA program, the acquisition of new knowledge represents, among others, a predominant outcome [9, 11, 12]. Well-aligned with the strategic objectives of CA programs [14], implicit forms of knowledge such as an entrepreneurial mindset or the different speed of working play a prominent role in the context of CAs [11]. Moreover, CAs collaborate with startups to complement the knowledge base of incumbents and compensate for deficits in technological advancements or market dynamics by absorbing explicit knowledge [24].

Gür [23] has shined a light on absorptive capacity theory to explain the ability of firms to adopt and transfer knowledge from the CA. To conceptualize absorptive capacity for the specific application to CAs, Gür [23] suggested a framework constituting of four factors that influence the knowledge transfer between CAs and the corporation: The antecedents and strategic objectives, the design components of the accelerator per se, as well as contingent factors such as the company size, the strength of its brand or the type of outcomes of the acceleration period [23]. In contrast, Chesbrough [26] found that absorptive capacity may not be the most appropriate way to successfully insource external knowledge. Instead, he recommends to purposefully manage knowledge flows by designing specific mechanisms to direct these inflows of knowledge [26]. Moreover, it is deemed critical for CAs to develop a specific process to manage the relationships between the business lines and the startups to allow for a successful transfer of knowledge from the CA to the parent organization [25]. This crucial role can be fulfilled by business developers who ensure the strategic fit between the firm and the startup, managing the interactions between the different stakeholders [25].

2.2.2 Other Outcomes: Besides the creation and transfer of knowledge, there are other outcomes of CAs. First, the startups can turn into paying customers after the completion of the program [21]. Moreover, startups can become suppliers, customers, or partners of the incumbent $[17,22]$. Gutmann et al. [10] provide another perspective suggesting that one outcome of CAs can be customers of the organizing firm benefitting from the enrichment of product offerings through integrated startup solutions. Hence, incumbent firms attempt to enrich products and services with incremental innovation created by the startups, which is then integrated into the offering of the firm $[10 ; 22]$.

Under the outcomes of CA programs for incumbents, it is pivotal to assess the factors which may positively influence the outcomes of CAs. Thus, providing implications or lists of success factors has provoked considerable attention in the field of CA research (e.g., [15, 22]). In general, among the authors who have provided different perspectives on success factors, some patterns could be derived from factors that have been mentioned across multiple publications (e.g., $[10,14,17,20]$. In that sense, success factors for CAs can be classified into seven distinct categories: (1) the ability to measure success, (2) the value proposition towards startups, (3) the competence to search and select complementing and high-potential startups, (4) the fixed timeframe of CAs, (5) the facilitation and realization of the collaboration between the CA, corporate actors and the startups, (6) C-level commitment, and (7) the definition of clear objectives.

On the other hand, within the context of CAs, as with every endeavor connected to entrepreneurship and innovation, there is a chance of failure. Common reasons for these are the competitive and ontological contradictions between corporates and startups with regard to cultural differences, power imbalances, and divergent modes of working as well as conflicting interests in resource allocation and speed $[5,9,18]$. In 
that sense, collaboration might be complicated by significant conflicts in basic beliefs as well as competitive contradictions [18]. Additionally, the attraction of promising startups and lack of needed internal resources are two essential failure factors [25]. Moschner and Herstatt [9], compared CA programs to green-washing activities and classified CAs as units that engage in entrepreneurial washing. In this view, CAs are mostly intended as symbolic action, with objectives lacking both the serious intention and execution beyond the displayed appearance towards the public. Such companies engage in trial-and-error with program structures and use CAs mainly to enhance their recognition as innovative players in the market [9]. The neglection of connecting startups to adequate corporate actors may lead to frustration on the startup's side as their main motivation to join CAs lies within the connection to the parent company [8].

\section{Methodology}

The empirical base of this research is a multiple case study [27]. To select the cases, we compiled a list of 77 European CAs plus information on their parental firms. The selected cases are heterogenous in order to reveal patterns across the population of strategic CAs focused on IT startups. In line with the objectives of this research, this sampling technique enabled data collection, providing the basis to describe and observe key themes of a phenomenon as any patterns that do emerge across heterogenous cases are likely to be of high value and represent key themes [28, 29]. Hence, we narrowed the list down by checking for active CAs. We then clustered these based on their heterogeneity, relevance to the study and access to sufficient data. According to Saunders et al. [28] applying heterogeneous or maximum variation sampling, demands choosing "participants with sufficiently diverse characteristics to provide the maximum variation possible in the data collected" [28, p. 301]. For the purpose of this research, we studied four CA programs of four corporations from the sample list. We conducted 13 semi-structured interviews ranging between 28 and 67 minutes as the primary means of data collection. The interviewees included active and former CA managers, CA managers employed by an external CA partner, employees from within the parent organization responsible for the collaboration, and a startup employee who was responsible for the participation in a CA program to allow for different perspectives in each case. We anonymize the cases and provide an overview of the interviews, case affiliation, and codes in Table 1.
Table 1 Overview of data sources

\begin{tabular}{|l|l|l|}
\hline Case & Data Sources & Code \\
\hline \multirow{4}{*}{$\begin{array}{l}\text { Primary } \\
\text { Data CA1 }\end{array}$} & Program Manager CA Paris & CA1, PM1 \\
\cline { 2 - 3 } & Program Manager CA Berlin & CA1, PM2 \\
\cline { 2 - 3 } & Program Manager CA Europe & CA1, PM3 \\
\cline { 2 - 3 } & OI Manager CA Europe & CA1, OIM \\
\cline { 2 - 3 } $\begin{array}{l}\text { Secondary } \\
\text { Data CA1 }\end{array}$ & Internal Documents, Website & CA1, SD \\
\hline \multirow{2}{*}{$\begin{array}{l}\text { Primary } \\
\text { Data CA2 }\end{array}$} & Program Manager CA (Partner Side) & CA2, PM1 \\
\cline { 2 - 3 } & Program Manager CA & CA2, PM2 \\
\cline { 2 - 3 } $\begin{array}{l}\text { Secondary } \\
\text { Data CA2 }\end{array}$ & Website, Annual Report & CA2, CLC \\
\hline $\begin{array}{l}\text { Primary } \\
\text { Data CA3 }\end{array}$ & Program Manager CA & Collaboration Lead Startup \\
\hline $\begin{array}{l}\text { Secondary } \\
\text { Data CA3 }\end{array}$ & Website, Annual Report, Magazines & CA3, SD \\
\hline $\begin{array}{l}\text { Primary } \\
\text { Data CA4 }\end{array}$ & Program Manager CA & CA4, PM \\
\cline { 2 - 3 } $\begin{array}{l}\text { Secondary } \\
\text { Data CA4 }\end{array}$ & Websitaboration Lead Business Unit & CA4, CLC \\
\hline
\end{tabular}

The semi-structured interviews were conducted using an interview guide including the identified themes and key questions necessary to answer the research questions. These included but were not limited to, the design, the process, the success measures, knowledge creation, transfer and adoption, success factors, and failure factors or obstacles. As each of the interviewees gave their consent, all interviews were recorded and then transcribed. In addition to this primary data, secondary data have been collected in each of the cases for the triangulation of the data. This includes data from publicly available sources, such as the CAs' websites, press releases, news articles, and reports, as well as data collected on the cases presented in peer-reviewed journals. Additionally, some of the interviewees provided confidential documents containing further information which were deemed relevant.

The qualitative data set has been analyzed following Thematic Analysis [30]. Hence, the research question served as initial guidance on which data to code. In total 71 different codes have been identified in the data set. To facilitate the process of coding, the authors have made use of the data analysis software NVivo. At first, the data has been coded according to predetermined themes with regard to objectives, design elements, obstacles and outcomes of CAs. Thereafter, we have searched for recurring relationships and patterns in the data to identify inherent themes that aid in answering the research question. These patterns have to a great extent emerged dynamically in the data across the interviews and ultimately led to the discovery of the role of the CA and the essential tasks of strategic CAs [28]. 
Table 2 Overview of the sampled cases

\begin{tabular}{|l|c|c|c|c|}
\hline Code & CA1 & CA2 & CA3 & CA4 \\
\hline $\begin{array}{l}\text { External } \\
\text { Partner }\end{array}$ & No & Yes & No & Yes \\
\hline Industry & Software & Fintech & IoT & AI \\
\hline $\begin{array}{l}\text { CA } \\
\text { Location }\end{array}$ & $\begin{array}{c}9 \text { global } \\
\text { locations }\end{array}$ & Paris & $\begin{array}{c}\text { Düssel- } \\
\text { dorf }\end{array}$ & Berlin \\
\hline $\begin{array}{l}\text { Relation } \\
\text { to HQ }\end{array}$ & Far & Close & Close & Far \\
\hline $\begin{array}{l}\text { Total } \\
\text { Startups }\end{array}$ & 279 & 43 & $50+$ & 7 \\
\hline Status & $\begin{array}{c}\text { Active } \\
\text { restructured }\end{array}$ & $\begin{array}{c}\text { Active } \\
\text { expanded }\end{array}$ & Active & Ended \\
\hline
\end{tabular}

Lastly, to provide sufficient context to this study it is relevant to differentiate the cases from each other, by highlighting distinct characteristics, thus, displaying their heterogeneity (see Table 2), with regard to the industries, the decision against or in favor of external accelerator partners and to the CA location, their maturity or program design, as for example, CA3 was the only case not following a batch-based, fixed timeframe in their CA program.

\section{Findings 4.1 Underlying Obstacles}

Our analysis revealed three dominant underlying obstacles of strategic CAs, (1) missing awareness, engagement, or resistance of corporate employees, (2) the difficulty of sourcing the right startups, and (3) the differences between large corporations and startups (see Appendix 1.1.).

First, not all employees of the parent cooperation may share the desire to collaborate with startups and integrate an external player into the corporate's ecosystem or solution. The data suggests that this may be attributed to a resistance to change or the external nature of the startups. Additionally, missing awareness of the program or the value of the program may contribute to this obstacle. According to PM2 of CA1, "having our whole corporation behind us is the most difficult one" [CA1, PM2]. Similarly, the CLC of CA2 states that ensuring the commitment of everyone involved is a big challenge. This big hurdle of missing internal alignment and confirmation can make it difficult to find someone internally who is ready to jump on a startups' solution. This missing internal support may be attributed to the missing awareness about the CA and its value in the parent corporation and see this as a challenge. Some interviewees attribute this missing internal commitment to the external nature of the startup solutions, which may be seen as competition rather than as being complementary. PM2 of CA2 described this problem accordingly: "let's say you are the champion working with a startup that is going to revolutionize a part of your business. How can [Corporate2] accept that a range of its revenues are going to depend on a startup? And what are the teams working within the business line going to think of themselves, if they realized that half of the value that they're going to create is coming from an external player?" [CA2, PM2]

In addition, to this problem stemming from the external nature of the startup solution, others have attributed the missing internal commitment or change resistance of the corporate employees. Accordingly, corporate employees are described as "very protective about the current status of things and current technologies, they want to keep everything as it was before because it's safer for them and it's easier not to change anything, just keep on doing what they've been doing forever" [CA2, PM1], further elaborating that "they don't see any obvious benefits of accepting or choosing the startup solution because they think that they have everything in place" [CA2, PM1].

Second, sourcing the right startups for the collaboration with the business units may prove to be difficult. Both the search and the selection contribute to this difficulty. The data implies a high resource intensity in search for the startups, strongly emphasizing this aspect. The selection necessitates ensuring both a fit between the selected business unit and the assessment of the ability of startups to deliver the expected results. This can be attributed to "failure from the startup side when they did not deliver what they promised to deliver" [CA2, PM1], or an insufficient fit or technical complexity of the integration, as well as insufficient care in the selection process lacking internal alignment. The difficulty in selection is further highlighted by CA4, PM stating that: "there are a lot of startups out there and the likelihood that you find a good match is not that high" [CA4, PM]. The obstacles with regard to the startup search led CA2 to partner up with an independent accelerator who takes over the sourcing as CA2, PM1 explains "the search is only on the [Partner] side. [...] we have around [...] a hundred VC analysts who do the search and [...] source the startups, depending on the needs and requests of [Corporate 2] so we can propose startups we think would be a good fit, we try to source specifically for their needs. " [CA2, PM1]

Third, the data suggest that the actual collaboration between the business units and the startups may be impeded by differences in size, speed, and culture between the startups and the incumbent. The internal culture in the parent corporation is seen as one of the biggest obstacles as processes in the parent corporation can be complex and are often lengthy. This includes integral processes for the CA programs such as the due diligence for the integration into the parent corporation's platform, and the 
protection of APIs necessary for the integration. In opposition to the slow processes in the incumbent firm, the process speed of the startups is seen as fast, an assessment that is evident throughout multiple data sources. This speed is necessitated by the financial constraints of the startups, which thus demand, or profit from a fast process of collaboration and integration. According to PM1 of CA2 these two actors, in addition to the differences in speed communicate differently: "Sometimes they speak really different languages. I mean, the startup and the managers. And sometimes we try to speak with them internally, both individually with the startup and then with the managers and try to actually like interpret a little bit for them to help them find the common ground. Because they were speaking about the same things, [in] different languages. I mean, not languages like foreign languages, but it was just different communication from both sides" [CA2, PM1]

These opposing speeds along with other differences in culture, such as communication, can lead to a culture clash between the corporates and the startups. Ostensibly, this culture clash plays an important role in the CA process. The PM of CA3 has explained the challenge of this culture clash accordingly: "Sometimes it's difficult to explain to startups, especially when they don't have a corporate background on the founders side why things move the way they move. And they also sometimes don't have the financial backing to wait for big corporate to come to a decision that might go either way after. That's one of the biggest challenges. " [CA3, PM]

According to the interviewed startup employee, this becomes especially problematic if the employees in the CA have "the glasses of the corporate" [CA, CLS] and cannot translate between the startups and the corporate. A related obstacle is the size difference between the accelerated startups and the parent corporations. According to the CLC of CA2, this size difference can be a big hurdle, if the importance of the project to the corporation does not fit the size of the startup: "there's a challenge between the size of the supplier, because at the end of the day, the startup is a supplier, [...] and we have to balance very well the size of the project and the size of the supplier. Because otherwise, we can have trouble [...] in the due diligence that we do every time we onboard a supplier. [...] because their activity is, you know, too bold too big in size, in magnitude, in terms of investment for the kind of supplier they represent." [CA2, CLC]

\subsection{The Role of the Strategic Corporate Accelerator}

Our data shows that the role of the CA in mitigating these obstacles and enabling collaboration can be divided into three essential tasks which have been derived from themes that have emerged through the analysis and coding of the data (see Appendix 1.2). These three essential tasks are: motivating, matchmaking, and mediating. Each of these essential tasks corresponds to one of the three identified underlying obstacles. This is illustrated in Figure 1.

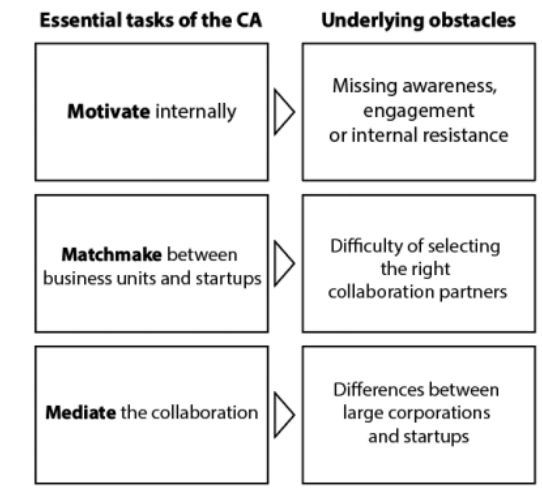

Figure 1 Essential tasks of the strategic $\mathrm{CA}$ and the corresponding obstacles

First, motivating is aimed towards mitigating the first obstacle of internal resistance. It includes advertising the program and the value it provides or may provide for the parental firm and its business units. Motivating internal stakeholders and creating awareness, as an essential task of a strategic CA is supported by various interviewees. For instance, PM2 of CA2 emphasized the process of "building and raising the visibility within [Corporate2] so all the business lines are aware of such programs and feel comfortable with working with startups within the accelerator" [CA2, PM2]. PM2 of CA1 supported this statement, adding the importance of communicating the value, "for every program, we have to first create awareness and we have to highlight what value we bring to [Corporate1] so that we can have the buy-in and agreement from our own people" [CA1, PM2]. This may involve changing the mindset of the employees: "that's part of our job to connect and to change the mindset within [Corporate1] employees" [CA1, PM2]. It became further evident in the data that the CAs may have to overcome internal resistance to innovation: "we try to actually convince the people who are skeptical. We [...] tried to show them the benefits of collaborating with startups" [CA2, PM1].

Second, matchmaking is aimed at resolving the difficulties associated with selecting the right 
collaboration. It involves internal and external scouting, due diligence of the startups, an assessment of the strategic fit between the business units and the startups, and aligning their expectations. PM2 of CA2 described this process of matchmaking as "to source startups, to find the right ones and to match them with the business line" [CA2, PM2]. Sourcing and selecting the optimal startups is seen as an essential task of the CA. The data suggests that it is not only considered important to identify the right startups but also to internally select the right business lines by assessing their needs and commitment beforehand. Multiple evidence in the data has suggested the importance of assessing the startups' capabilities to deliver on the expected results. Moreover, compatibility with the corporate and the first judgement of startups by the corporate actors are deemed important. The external and, more importantly, the internal networks of the CA employees may be crucial for fulfilling this task sufficiently. Additionally, the data has revealed the need to align expectations of business units and startups prior to the acceleration, to request commitment of both parties and to address political and processual challenges in the corporate setting.

Third, mediating is targeted towards mitigating the differences between the parental corporation and the startups, in terms of size, speed of processes, and culture. Mediating includes translating between these two stakeholders, facilitating the collaboration by enabling or speeding up processes, as well as ensuring the continuous commitment of the involved actors. CLC from CA 2 described this role as the CA being the "referee in the match between startups and corporate champions" [CA2, CLC]. Similarly, the PM of CA2 claimed "for some reasons, it works better when there is a mediator" [CA2, PM1]. Therefore, the CA may act as a translator between the startups and corporates, explaining the cultural and social differences to align expectations and improve the collaboration. As they "sometimes speak really different languages" [CA2, PM1] the CAs may aim to become "a translator between the two worlds" [CA3, PM].

The data further indicated that the CA may continuously measure outcomes by monitoring commitment and tracking progress, as well as resolving concerns and potential frictions or misbehaviors within the collaboration of both sides. A structured program, with specific milestones and a set deadline, may be used to ensure this commitment. Further, the CA may try to remove impediments and ease the process of collaboration by providing the technical infrastructure, accelerating internal processes, or managing complex approval flows, thus facilitating the inherent processes. The data suggest, that after the acceleration process, the CA may use results for motivation, essentially creating a positive reinforcement loop, which is depicted in Figure 2. This may involve measuring the results and the value and effectiveness of the CA. It may also be used to convince top management of the overall performance and, thus, to ensure top management support.

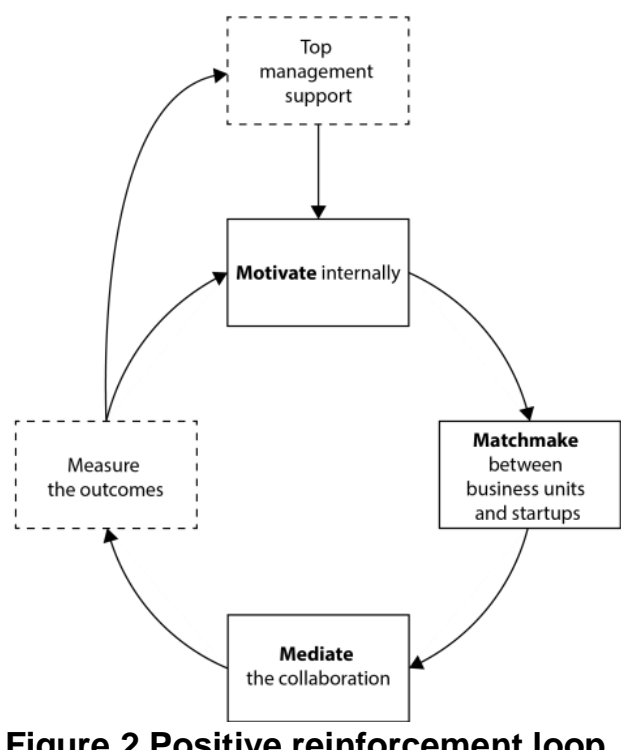

Figure 2 Positive reinforcement loop

The broader analysis of the different facets of the sampled CA programs with regard to design options of strategic CAs and the motivations behind them, served as the foundation for the proposed framework showcasing the underlying role of the strategic CA. The framework is illustrated in Figure 3. It intends to depict the role of the strategic CA in enabling startup partnerships and OL for the parental firm. This illustration visualizes the $\mathrm{CA}$ in the parental firm's ecosystem to emphasize the strategic $\mathrm{CA}$ as an enabler and facilitator of collaborations between parts of the large parental firm and the small startups. The components of the essential tasks of the strategic CA are shown for each of the stakeholders of the CA process. As depicted, the task of mediating is targeted towards reducing the underlying obstacles of the collaboration. As important but optional relations, the tasks towards ensuring top management support and including customers in the collaborations are included.

The role of the strategic CA may also comprise the parent corporation's customers as stakeholders. The essential tasks are found to be similar to those necessary in the collaboration between the business units and the startups as can be observed in Figure 1. The CA may involve customers early in the collaboration. Ideally, they are already involved before the pre-acceleration. Thereby, the underlying customer's needs must be meticulously researched to derive and identify a suitable solution for this in the 
form of startup solutions. These activities of the CA result also in a key driver to attract startups to the program as "our treasure box is access and exposure to more than four hundred thousand customers that [Corporate1] has" [CA1, PM2].

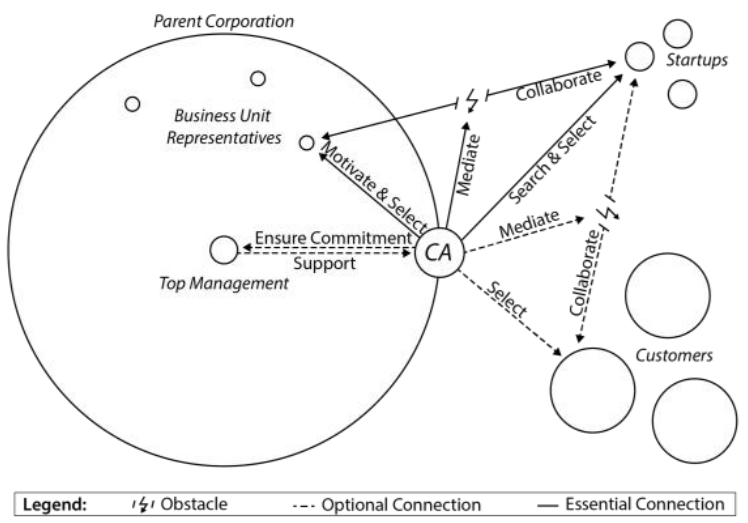

Figure 3 Framework role of the strategic CA

Concluding from the above, we find that the strategic CA connects the adequate stakeholders and enables or facilitates their collaboration. Thereby, the strategic CA should focus on accelerating the collaboration rather than the startup itself. In this role, CAs mainly need to concentrate on the tasks of motivating, matchmaking, and mediating between the stakeholders of the program, to mitigate the underlying obstacles of the collaboration and ensure successful future viability.

\section{Implications 5.1 Theoretical Implications}

To highlight our contribution, we juxtapose our findings with prior literature. We identified three underlying obstacles: missing company support, difficulty of startup scouting, and vast differences between startups and large corporations in terms of size, speed, and culture. These findings are consistent with prior literature (see $[8,9,18,25]$ ) and give salience to the fact that the differences between startups, and large corporations are characterized by "significant tensions in values, perceptions and modes of operation" [18, p. 18]. Our findings extend the literature by positioning these obstacles in light of the different tasks that are essential for an effective design of a strategic CA. This understanding enriches how future scholarship can engage with the concept of strategic $\mathrm{CA}$ and how it can be positioned to mitigate these obstacles through its essential tasks.

In this regard, we propose a framework unpacking the role of the strategic CA. The framework offers a different perspective from prior CA literature where the tasks of the CA are usually presented in a sequential process logic (e.g., [4, 22, 23]). We take a perspective that present their role within their ecosystem and showcase the different actors in the CA process and their relationships. This allows for an understanding of the design elements and builds on the perspective by scholars such as Nesner et al's. [24] focus on the knowledge flow between the actors involved in the CA process.

Our study goes one step further by identifying the essential tasks of a strategic CA in its underlying role: motivating internally, matchmaking between the business units and the startups, and mediating the collaboration. To the best of our knowledge, no CA scholar has so far explicitly highlighted the tasks of motivating internally to create awareness and to mitigate change resistance as an essential task of the strategic CA. Yet, our study shows that these are important, if not critical, role-defining tasks for a strategic CA that holds important implications for how we engage with the concept of strategic CAs in scholarship and practice. We suggest that the absence of this role may preclude scholars from an important consideration in the effective design of CAs and may contribute to why many CAs have a fleeting shelf life before running aground. Furthermore, in consonance with Gutmann et al. [8], our findings on matchmaking reveal that the neglection of connecting startups to the adequate corporate actors may lead to frustration on the startup's side as their main motivation to join CAs lies within the matchmaking and connection to the parent company. This is in contrast with prior literature that present CA employees as bridge makers [17] or boundary-spanners [25] at the individual employees level, which is limited to the knowledge flows in the acceleration process. Thus, these notions do not capture what we find and describe with the tasks of mediating and matchmaking between the involved actors to achieve a successful partnership.

Through presenting the CA in such a way and identifying the essential tasks and the underlying role of a strategic CA, we enrich the understanding of strategic CAs in the literature by providing a different perspective on the phenomenon. With this understanding of the phenomenon, we have been able to unveil key roles that should serve as pertinent implication for design elements of a strategic CA. Accordingly, we propose that an effective strategic CA should be primarily designed to optimally fulfill its role, rather than by simply following a list of design elements as, for example, proposed by Kohler [17] that are based on the independent accelerator literature and then adopted to the CA phenomenon. However, doing this will require a clear understanding of the roles of a strategic CA. We believe we have only scratched the 
surface in this line of inquiry and the opportunity for future research to further sharpen our understanding in this regard remains vast.

\subsection{Managerial Recommendations}

Our research suggests that effective design should not be based on the manifestations of the individual design elements but rather on the optimal fulfillment of the underlying role of strategic CAs. When creating or redesigning a strategic CA program, there is value in considering the essential tasks the CA should fulfill. Only subsequently should the optimal configuration of the individual design elements required for their specific context be considered. We suggest that a strategic CA program should strive to mitigate the underlying obstacles and leverage the essential tasks to foster successful collaborations.

Based on our findings, for practitioners aiming for their CA to fulfill the tasks of motivating internally and matchmaking (i.e., selecting the right business unit representatives while being able to scout and attract the right startups), the choice of location and integration is essential to enable direct contact and short lines of communication. Also, to fulfill the three identified tasks, the team composition may derive value from possessing both strong internal and external networks as well as an understanding of both large incumbents' and startups' ways of working.

Considering the process design elements of search and selection, the essential task of matchmaking implies a close involvement of the participating business units in this process, searching for startups that fulfill their needs, and selecting those with optimal strategic fit and ability to deliver. A batch logic with a fixed timeframe may be beneficial to ensure commitment and accountability from the actors involved in the acceleration process. With regard to the program offering, the essential tasks of the CA imply a focus on collaborative projects with the business units to test and prepare a subsequent partnership. Thus, a focus should be placed on individual support for the startups and the collaborations rather than on educational offerings. This has further implications on the number of startups of an individual batch or cohort, which should be limited to a manageable number of startups that can be supported individually. The necessity of motivating internally to create awareness and mitigate change resistance implies the value of implementing success measures for the program to prove effectiveness and value to the parental firm. These success measures as proof of effectiveness and value can motivate internally and reinsure management support to create a positive reinforcement loop for the CA program.

\subsection{Limitations and Future Research}

As with any scientific work, there are limitations to this paper. The first limitation stems from the qualitative research design chosen, which implies a limit to the generalizability of the study's results. We thus call for further research adopting other generalizable methods to examine these results further. For example, the relationships between stakeholders and the essential tasks of the CA could be further studied in a larger sample. Moreover, the authors do not claim that the analysis based on a heterogeneous sample of four cases is sufficient to explain the underlying evolution of strategic CAs in its entirety. Nevertheless, we provide a sound starting point for further research to investigate the construct of strategic CAs from this novel angle taking into account the underlying role of the CA. Our study is well suited to initiate a discussion on the shortcomings of the current understanding of strategic CAs and the efficacy of their design.

We encourage further research on the effective configurations between the role of context, resource availability, objectives of the $\mathrm{CA}$, and the structure and uniqueness of the parental organization and its environment, in finding the optimal design . Lastly, this research has mostly focused on examining CAs from the parent corporations' perspective. Thus, it might be beneficial for future research to take a startups' perspective to explore how their interests may converge or diverge from the corporates'.

\subsection{Conclusion}

Our approach to provide recommendations for a well-orchestrated design for strategic CAs has been to study the multifaceted CA process and the existing design manifestation in a heterogeneous multiple case study in the digital context. In the process we have found three underlying obstacles of the collaboration between the business units and the startups: the missing awareness or resistance of the corporate employees, the difficulty of sourcing the right startups, and the differences between corporations and startups.

While valuable on their own, these findings on the underlying obstacles function as the foundation for the identified role of strategic CAs presented in our advanced framework. The proposed role is based on the finding that the essential tasks of the CA are aimed at mitigating the underlying obstacles of the collaboration between corporates and startups. The essential tasks of the strategic CA to mitigate these obstacles that have been identified are: motivating internally, matchmaking between the startups and the business units, and mediating the collaboration by 
translating, facilitating, and ensuring commitment. In summary, our findings imply that if a strategic CA is designed to optimally fulfill its role in the ecosystem, i.e., through motivating, matchmaking, and mediating, it may be able to mitigate the underlying obstacles hindering the collaboration between business units and startups. Consequently, by positioning and designing a $\mathrm{CA}$ in such a manner, the strategic CA has the potential to be more than an entrepreneurial washing unit with the sole purpose of providing an innovative image as described by Moschner and Herstatt [9].

\section{References}

[1] Davila, T. (2014). The Innovation Strategy Big Companies Should Pursue. Harvard Business Review.

[2] Hochberg, Y. V. (2016). Accelerating entrepreneurs and ecosystems: The seed accelerator model. Innovation Policy and the Economy, 16(1), 25-51.

[3] Dörner, K., Flötotto, M., Henz, T., \& Stralin, T. (2020). You can't buy love Reimagining corporate-startup partnerships in the DACH region.

[4] Shankar, R. K., \& Shepherd, D. A. (2019). Accelerating strategic fit or venture emergence: Different paths adopted by corporate accelerators. Journal of Business Venturing, $34(5)$.

[5] Weiblen, T., \& Chesbrough, H. W. (2015). Engaging with startups to enhance corporate innovation. California Management Review, 57(2), 66-90.

[6] Crișan, E. L., Salanță, I. I., Beleiu, I. N., Bordean, O. N., \& Bunduchi, R. (2021). A systematic literature review on accelerators. Journal of Technology Transfer, 46(1), 62-89. [7] Kurpjuweit, S., \& Wagner, S. M. (2020). Startup Supplier Programs: A New Model for Managing CorporateStartup Partnerships. California Management Review, 62(3), 64-85.

[8] Gutmann, T., Maas, C., Kanbach, D., \& Stubner, S. (2020). Startups in a corporate accelerator: what is satisfying, what is relevant and what can corporates improve. International Journal of Entrepreneurship and Innovation Management, 24(6), 413.

[9] Moschner, S.-L., \& Herstatt, C. (2017). All That Glitters Is Not Gold - How Motives for Open Innovation Collaboration with Startups Diverge from Action in Corporate Accelerators (No. 102).

[10] Gutmann, T., Kanbach, D., \& Seltman, S. (2019). Exploring the benefits of corporate accelerators: Investigating the SAP Industry 4.0 Startup program. Problems and Perspectives in Management, 17(3), 218-232. [11] Urbaniec, M., \& Żur, A. (2020). Business model innovation in corporate entrepreneurship: exploratory insights from corporate accelerators. International Entrepreneurship and Management Journal.

[12] Cohen, S., Fehder, D. C., Hochberg, Y. V., \& Murray, F. (2019). The design of startup accelerators. Research Policy, 48(7), 1781-1797.

[13] Pauwels, C., Clarysse, B., Wright, M., \& Van Hove, J. (2016). Understanding a new generation incubation model: The accelerator. Technovation, 50-51, 13-24.
[14] Kanbach, D. K., \& Stubner, S. (2016). Corporate accelerators as recent form of startup engagement: The what, the why, and the how. Journal of Applied Business Research, 32(6), 1761-1776.

[15] Jackson, P., Richter, N., \& Schildhauer, T. (2015). Open Innovation with digital startups using Corporate Accelerators - A review of the current state of research. Policy Advice and Political Consulting, 7(4), 152-159.

[16] Cohen, S., \& Hochberg, Y. V. (2014). Accelerating Startups: The Seed Accelerator Phenomenon. SSRN Electronic Journal, 1-16.

[17] Kohler, T. (2016). Corporate accelerators: Building bridges between corporations and startups. Business Horizons, 59(3), 347-357.

[18] Jackson, P., \& Richter, N. (2017). Situational Logic: An Analysis of Open Innovation using Corporate Accelerators. International Journal of Innovation Management, 21(7).

[19] Hausberg, J. P., \& Korreck, S. (2020). Business incubators and accelerators: a co-citation analysis-based, systematic literature review. The Journal of Technology Transfer, 45(1), 151-176.

[20] Bergmann, T., \& Rothausen, T. (2020). Supporting startups in the process industries with accelerator programs: Types, design elements and success measurement. Journal of Business Chemistry, October 2020, 81-109.

[21] Moschner, S.-L., Fink, A. A., Kurpjuweit, S., Wagner, S. M., \& Herstatt, C. (2019). Toward a better understanding of corporate accelerator models. Business Horizons, 62(5), 637-647.

[22] Richter, N., Jackson, P., \& Schildhauer, T. (2018). Outsourcing creativity: An abductive study of open innovation using corporate accelerators. Creativity and Innovation Management, 27(1), 69-78.

[23] Gür, U. (2021). Absorptive Capacity Approach to Technology Transfer at Corporate Accelerators: A Systematic Literature Review. In FGF Studies in Small Business and Entrepreneurship (pp. 51-69). Springer.

[24] Nesner, T., Eismann, T. T., \& Voigt, K.-I. (2020). It's a match! Building relationships between corporates and startups throughout Corporate Accelerators. In Journal of Technology and Innovation Management (Vol.4, Issue 1). [25] Mahmoud-Jouini, S. Ben, Duvert, C., \& Esquirol, M. (2018). Key Factors in Building a Corporate Accelerator Capability: Developing an effective corporate accelerator requires close attention to the relationships between startups and the sponsoring company. Research Technology Management, 61(4), 26-34.

[26] Chesbrough, H. (2019). Open Innovation Results. In Open Innovation Results. Oxford University Press.

[27] Yin, R. K. (2014). Case study research and applications: Design and methods. Sage publications.

[28] Saunders, M., Lewis, P., \& Thornhill, A. (2016). Research Methods for Business Students (7th Edition).

[29] Patton, M. Q. (2002). Qualitative Research And Evaluation Methods. Sage Publications.

[30] Braun, V., \& Clarke, V. (2006). Using thematic analysis in psychology. Qualitative Research in Psychology, 3(2), $77-1$ 
Appendix

Appendix 1.1: Dominant underlying obstacles of strategic CAs

\begin{tabular}{|c|c|c|c|}
\hline $\begin{array}{c}\text { Code } \\
\text { Level } 1\end{array}$ & $\begin{array}{c}\text { Code } \\
\text { Level } 2\end{array}$ & $\begin{array}{c}\text { Code } \\
\text { Level } 3\end{array}$ & Quotation Example \\
\hline \multirow{14}{*}{ Obstacles } & \multirow{5}{*}{$\begin{array}{c}\text { Missing } \\
\text { Commitment }\end{array}$} & \multirow{2}{*}{ Internal Engagement } & $\begin{array}{c}\text { "So there are hundreds of different hurdles and obstacles. The first one being internal engagement. In many cases, we have } \\
\text { created solutions, but poor engagement from the business lines to work with them." [CA2, PM2] }\end{array}$ \\
\hline & & & "Having our whole corporation behind us is the most difficult one." [CA1, PM2] \\
\hline & & $\begin{array}{l}\text { Disrupting Internal } \\
\text { Units }\end{array}$ & $\begin{array}{l}\text { "Let's say you are the champion and working with a startup that is going to revolutionize a part of your business. How can } \\
\text { [Corporate 2] accept that a range of its revenues are going to depend on a startup. And what are the teams working within the } \\
\text { business line are going to think of themselves, if they realized that half of the value that they're going to create is coming } \\
\text { from an external player?" [CA2, PM2] }\end{array}$ \\
\hline & & $\begin{array}{l}\text { Not known in the } \\
\text { Organization }\end{array}$ & "We need more of showing the world and also the internal world what kind of cool startups we have as partners." [CA1, OIM] \\
\hline & & Political Obstacles & $\begin{array}{c}\text { "There were two things coming from [Corporate 4]. The whole corporate had a very big reorganization which also changed } \\
\text { budget responsibilities that were all rearranged. And people are very busy implementing this change and they don't know, OK, } \\
\text { who do I have to talk to now to get permissions or whatever?" [CA4, PM] }\end{array}$ \\
\hline & \multirow{4}{*}{$\begin{array}{l}\text { Difficulties in } \\
\text { Selection }\end{array}$} & $\begin{array}{l}\text { Customer } \\
\text { Expectations }\end{array}$ & $\begin{array}{l}\text { "you need to bring in - and that's what we didn't do so much - (...) customer feedback, very early, and don't build too long on } \\
\text { an integration. And don't think when you talk to a customer you want to sell it, you have to get the feedback. It's purely the } \\
\text { feedback. And that's something... (...) don't think as a perfectionist in a sense of it needs to be perfectly integrated, then I sell } \\
\text { it, but rather have (...) validation points. You have to find a way that you have a customer who gives you feedback" [CA1, PM3] }\end{array}$ \\
\hline & & Startup Performance & $\begin{array}{l}\text { "but sometimes (...) they do not take this partnership very serious (...) More I would say it was just failure from the startup side } \\
\text { when they did not deliver what they promised to deliver and they just did not finish the program" [CA2, PM1] }\end{array}$ \\
\hline & & Startup Selection & $\begin{array}{l}\text { "the failure adds up. Yeah, so you selected a startup and it turns out to be not the perfect startup. Then the processes at } \\
\text { [Corporate1] are difficult. The customer situation is difficult. (...) If somebody says, could you do better? [CA1, OIM] }\end{array}$ \\
\hline & & Internal Selection & $\begin{array}{c}\text { "Or there are also internal dynamics that it's not always that easy to find someone who is ready to jump on a partner } \\
\text { solution." [CA1, PM2] }\end{array}$ \\
\hline & \multirow{5}{*}{$\begin{array}{l}\text { Differences } \\
\text { between } \\
\text { Startups and } \\
\text { Corporates }\end{array}$} & \multirow[t]{2}{*}{ Corporate Culture } & $\begin{array}{l}\text { "Sometimes it's difficult to explain to startups, especially when they don't have a corporate background on the founders side } \\
\text { why things move the way they move. And they also sometimes don't have the financial backing to wait for big corporate to } \\
\text { come to a decision that might go either way after. That's one of the biggest challenges." [CA3, PM] }\end{array}$ \\
\hline & & & "one of the biggest obstacles is the internal culture, I would say, within the organization" [CA2, PM] \\
\hline & & Culture Clash & $\begin{array}{l}\text { "sometimes they speak really different languages, the startup and the managers. And sometimes we try to speak with them } \\
\text { internally, both individually with the startup and then with the managers, and try to interpret a little bit for them to help them } \\
\text { find the common ground, basically. Because they were speaking about the same things, but different languages" [CA2, PM1] }\end{array}$ \\
\hline & & Speed & $\begin{array}{l}\text { "The first thing that comes up in my mind is the pacing of decisions. I mean, startups decide on the, how do you say, on the } \\
\text { doorstep (...) And corporates have a long decision process" [CA4, CLC] }\end{array}$ \\
\hline & & $\begin{array}{l}\text { Technology } \\
\text { Openness }\end{array}$ & $\begin{array}{l}\text { "And that's why I think for us at [Corporate } 1] \text { it is so crucial that the business technology platform gives easy access for } \\
\text { startups. And it's not complicated. And it's like for free. You learn easily how to do it. (...) In a way our processes are a complete } \\
\text { failure. As I said, we don't have easy access for startups. We don't have easy access to test systems. We don't have a good } \\
\text { education for startups" [CA1, OIM] }\end{array}$ \\
\hline
\end{tabular}

\begin{tabular}{|c|c|c|}
\hline \multicolumn{3}{|c|}{ Appendix 1.2: The role of the strategic $C A$} \\
\hline \begin{tabular}{c|c|} 
Code \\
Level 1
\end{tabular} & $\begin{array}{c}\text { Code } \\
\text { Level } 2\end{array}$ & Quotation Example \\
\hline \multirow{3}{*}{$\begin{array}{l}\text { Motivate } \\
\text { Internally }\end{array}$} & $\begin{array}{l}\text { Overcome Corporate } \\
\text { Resistance }\end{array}$ & "That's part of our job to connect it and to change the mindset within [Corporate1] employees" [CA1, PM1] \\
\hline & \multirow{2}{*}{$\begin{array}{l}\text { Raising Internal } \\
\text { Awareness }\end{array}$} & $\begin{array}{l}\text { "So for every program, we have to first create awareness and we have to kind of highlight what value we bring to [Corporate1] so that we can } \\
\text { have the buy-in and agreement from our own people." [CA1, PM2] }\end{array}$ \\
\hline & & $\begin{array}{l}\text { "And we are building and raising the visibility of the program within [Corporate 2]. So all the business lines are aware of such programs and } \\
\qquad \text { feel comfortable with working with startups within the accelerator" [CA2, PM2] }\end{array}$ \\
\hline \multirow{3}{*}{ Matchmake } & Selection \& Scouting & "to source startups, to find the right ones and to match them with the business lines (...)" [CA2, PM2] \\
\hline & \multirow{2}{*}{$\begin{array}{l}\text { Networking \& } \\
\text { Matchmaking }\end{array}$} & $\begin{array}{l}\text { "they had a very regular exchange with the business unit, that was also something we asked our colleagues from the business that they should } \\
\text { support with technical, but also with business knowhow because we felt that this is something where [Corporate4] could really add some } \\
\text { value or give some benefit to the startups." [CA4, PM] }\end{array}$ \\
\hline & & $\begin{array}{l}\text { "I think the key role would be identifying the right startups and knowing that, oh, this startup absolutely fits with this product. We need this. } \\
\text { Our customers need this. So having the overview and the sharpness to understand if the startup is a high potential and kind of expose them to } \\
\text { our internal stakeholders would be, to be honest, the main responsibility here or it's key" [CA1, PM2] }\end{array}$ \\
\hline \multirow{7}{*}{ Mediate } & $\begin{array}{l}\text { Address Questions \& } \\
\text { Obstacles within LoBs }\end{array}$ & $\begin{array}{r}\text { "They were also the people to ask questions, to, if there were any if there was anything during the process, so they were there, the ones } \\
\text { leading through the process." [CA4, CLC] }\end{array}$ \\
\hline & $\begin{array}{l}\text { Cloud \& Technical } \\
\text { Support }\end{array}$ & $\begin{array}{l}\text { "And of course benefit is also that they have people, technical architects, who work with them on the integration because it's really } \\
\text { complicated" [CA1, PM3] }\end{array}$ \\
\hline & \multirow{2}{*}{ Go-To-Market Support } & $\begin{array}{l}\text { "we push them through the app centre and then introduce them to account executives or [Corporate1] gets and try to have customer } \\
\text { exposure." [CA1, PM2] }\end{array}$ \\
\hline & & $\begin{array}{l}\text { "a startup has a very hard time approaching these big companies because they are not prepared to have bus iness with such a small player (...) } \\
\text { if you go there together, then this can open some doors. And so this is also where we offered our support" [CA4, PM] }\end{array}$ \\
\hline & \multirow{3}{*}{ Mediator } & "We try to mitigate that by setting expectations for the startups becoming a translator between the two worlds." [CA3, PM] \\
\hline & & $\begin{array}{l}\text { "obviously they can do it themselves, but from my experience, it just works better. For some reasons, it works better when there is a mediator } \\
\text { (...) the mediator because we understand also both (...) But we understand very well the problems that they have within the bank. But we also } \\
\text { have a lot of connections with the startup world, like the speed with which the startups are working and the same with the colleagues, } \\
\text { because we work together as one team." [CA2, PM1] }\end{array}$ \\
\hline & & $\begin{array}{c}\text { "A mediator before the conflict is there. And it's change management for a lot of our established developers and departments, it's change } \\
\text { management to be open." [CA1, OIM] }\end{array}$ \\
\hline Other & $\begin{array}{l}\text { Collaboration with } \\
\text { Customers }\end{array}$ & $\begin{array}{l}\text { "I'm responsible for collaboration together with our external partners, meaning mostly our customers who want to do in some sort of way a } \\
\text { corporation or open innovation together with [Corporate3]." [CA3, PM] }\end{array}$ \\
\hline
\end{tabular}

